\title{
LA IMPORTANCIA DE LA ARGUMENTACIÓN EN LA BIOÉTICA'
}

The Importance of Argumentation in Bioethics ${ }^{1}$

$\underline{\text { Lucio Alfonso Rubio Antelis }}^{2}$

Fecha de Recepción: Mayo 5 de 2014

Fecha de Aceptación: Mayo 12 de 2014

SUMARIO: 1. Introducción; 2. Bioética y argumentación en el ámbito de la globalización; 3. Los principios fundamentales de la Bioética; 4. Conclusiones; 5. Referencias bibliográficas

${ }^{1}$ Investigación realizada en el transcurso de los estudios de doctorado en Derecho Constitucional por la Universidad de Castilla-La Mancha.

${ }^{2}$ Abogado. Especialista en Derechos Humanos y doctorante en Derecho Constitucional por la Universidad de Castilla-La Mancha, España; Doctor en Derecho y Globalización, en el Programa Nacional de Posgrados de Calidad financiada por CONACYT México; Autor y compilador de diversos textos jurídicos en materia de argumentación jurídica, derecho procesal penal y garantismo penal. 


\section{COMO SE CITA ESTE ARTÍCULO (APA 6)}

Rubio Antelis, L. A. (2014) La importancia de la argumentación en la Bioética. (Y. Carrillo De la rosa, Ed.) Revista Jurídica Mario Alario D'Filippo, VI (12), pág. 108-120

\section{RESUMEN}

Los derechos humanos constitucionalizados, así como la forma de hacerlos una realidad, definen la transición de los estados hacia la globalización jurídica. La bioética como una de las disciplinas del Estado de Derecho, debe mutar su actual discurso, caracterizado por su inmanencia academicista, hacia una realidad palpable. El uso y aplicación de la argumentación jurídica hacia el respeto de la dignidad humana, sin duda alguna servirá como instrumento transformador del escenario discursivo de la bioética contemporánea, proponiéndose como una garantía de los derechos esenciales del hombre.

\section{PALABRAS CLAVE}

Bioética, argumentación jurídica, globalización, Estado de derecho, derechos humanos.

\section{ABSTRACT}

Constitutionalized human rights and how to make them a reality, define the transition of states towards legal globalization. Bioethics as one of the disciplines of the rule of law, must mutate its current discourse, characterized by its academic immanence, into a reality. The use and application of legal arguments towards respect for human dignity undoubtedly serve as instrument transformer discourse scenario of contemporary bioethics, proposing as a guarantee of the essential rights of man.

\section{KEYWORDS}

Bioethics, legal argument, globalization, rule of law, human rights. 


\section{INTRODUCCIÓN}

El fenómeno de la globalización en la primera década del siglo XXI, ha dejado la marca de una significativa característica en el orden normativo: La incipiente crisis del derecho y el renacimiento de las caras ocultas del exterminio humano.

En el orden jurídico interno, las nuevas reglas impuestas por los imperios transnacionales y por los poderes supraestatales internacionales, ponen en crisis una serie de valores elementales y vitales para la especie humana: la preservación del respeto a los estados de derecho democrático y social; la dignidad del hombre como marco base de los derechos humanos; la cultura; la identidad; la organización; la seguridad y toda organización social.

Nuestra contemporánea sociedad enfrenta diversas aporías frente a un neoliberalismo multifacético, cristalizado en el seno de diversos organismos mundializados forjadores del fenómeno globalizador. En el orden local, sobresale la percepción de la seguridad interna de la sociedad mexicana. Se advierte una constante desconfianza hacia las instituciones procuradoras y administradoras de justicia.

La seguridad pública y las instituciones encargadas de velar y guardar por la paz y el orden social, han sido rebasadas por la delincuencia en general, generándose mayores índices delictivos que han lesionado a la sociedad vulnerable, indefensa, desconfiada de las agencias policiacas que se encuentran involucradas con los organismos delictivos.

Se reafirma la crisis del derecho penal, al resultar insuficiente la capacidad investigadora del Estado frente a un mayor impacto de comisión de hechos ilícitos surgidos desde las fuerzas salvajes, clandestinas y letales de grupos delictivos armados, hasta la violencia oficial derivada de los actos de corrupción y violación de derechos humanos de los cuerpos policiacos y militares.

La vida humana ha sido objeto de escarnio y de burla por los medios impresos que muestran la virulenta descomposición social. Sin embargo la vida humana es el principal valor reconocido por cualquier sociedad organizada, por ello toda incursión biomédica en los seres humanos a nivel de investigación ha sido regulada bajo estándares internacionales (CIOMS, 2002). También la vida humana, es el principal objeto de estudio y razón de ser de la bioética, entendiéndola como la ética aplicada que precisamente estudia la conducta ética de los hombres, que toma al hombre de la ciencia de la medicina como ejemplo y que privilegia a fin de exigirle sobre todo el respeto al bios, es decir a la vida humana plena. (Pfeiffer, 2011)

No obstante, precisamente las críticas que recibe el discurso de la bioética contemporánea, están centradas por un excesivo entorno académico presentándose a la sociedad con discursos y tópicos difíciles y complicados encapsulados y exhibidos en laboratorios académicos. Este aislamiento cientificista lo separa en algunas ocasiones, de los graves problemas que se presentan a nivel mundial como es el calentamiento global, contaminación ambiental, problemas de salud pública, entre otros. En suma, estos deberían ser los retos que en la actualidad afrontaría el pensamiento de 
la bioética hacia propuestas realistas, viables y totalmente axiológicas que permitan recuperar la calidad humana de esta disciplina.

En este espacio se pretende introducir a la argumentación jurídica como una herramienta que acceda a los contextos del pensamiento progresista de la bioética en la última década, en la cual la bioética y el derecho se encaminan hacia senderos que unifican su relevancia social. En este sentido se tratará de exponer la necesidad de separar al positivismo jurídico de influencia kelseniana (Cardona, 2011) respecto a las tesis principales de la bioética, adoptando tanto un lenguaje, como un modelo teórico y práctico enfocado a la realidad social y mundial que vivimos.

Por ello el paradigma interpretativo viene a corresponder a la argumentación normativa que se expone como una instancia más conveniente y más viable para incidir en la solución de los problemas contemporáneos que ponen en serio peligro a la vida humana en la era de la globalización. Según González Ibarra (como se citó en Obando \& Tejeda, 2011), estas ideas agrupadas en el modelo teórico que se presentan en este apartado, también se proponen para impulsar la investigación docente en los ámbitos humanísticos, filosóficos y jurídicos, que deban incorporarse en los programas de estudios de las diferentes casas de estudio tanto privadas como públicas ${ }^{3}$.

\section{BIOÉTICA Y ARGUMENTACIÓN EN ELÁMBITO DE LA GLOBALIZACIÓN}

Se ha indicado que la bioética está sustentada por objetivos del bien común que irradian la felicidad y el bienestar para todos los seres humanos. Los compromisos y la conjunción de propuestas permitirán construir una comunidad tanto local como mundial preocupados por el devenir del globo terráqueo y el destino de las generaciones que se encuentran en la actualidad en estado de incertidumbre ante la serie de peligros y amenazas por las que atraviesa actualmente la humanidad.

En este sentido resulta altamente preocupante la falta de previsión, prevención y control de políticas mundiales en cuanto al uso de la energía, derivada principalmente del abuso del carbono, productos derivados del petróleo y otros componentes químicos que han desestabilizado el medio ambiente global, aunado al aumento del desempleo, la destrucción de familias, la pobreza, la violencia oficial y delincuencial y el hambre.

Agregándose también la voracidad insaciable de las industrias de la minería, petroquímicas, plantas nucleares y otras que ponen en riesgo la vida humana en general, la fauna y flora silvestre, así como la estabilidad de los ecosistemas y tienden a contaminarlos en forma irreversible. Tal preocupación fue consagrada en la Declaración del Parlamento de las Religiones del Mundo en el año de 1993. (Bermejo \& Belda, 2006)

No obstante la vida humana es aún el principal objeto de estudio de la bioética, ya que al ser una

${ }^{3}$ Sobre este tenor se retoma la propuesta basada en que el aprendizaje de estas ciencias y disciplinas, deban ser impulsadas y consagradas en los programas de estudio vigentes en universidades y centros de educación superior tanto público como privado. 
disciplina científica tiene como finalidad efectuar el análisis racional de los problemas morales ligados a la protección de la vida humana por medio de la medicina, sus relaciones con el derecho y otras ciencias naturales y sociales, originando en conjunto la necesidad de juridificar los principios rectores para el respeto, preservación y mejoramiento de la calidad de vida, procurando antes que todo la formación integral de la personalidad humana en sus aspectos físico, mental y social. (Sánchez Gómez, 2009)

La aparición de diversas tecnologías, conocimientos científicos, así como disciplinas en el ámbito de la bioética ha dado lugar a diferentes concepciones y a diversas críticas en torno a esta problemática (Aparisi Miralles, 1997). Por un lado se establece la existencia de la economía y la política que provocan la existencia de relaciones surgidas entre el bioderecho, la biopolítica y la bioeconomía, sin desatender a las llamadas biotecnologías. Esta pluralidad de conceptos y de conocimientos, se encuentran relacionados con diversos fenómenos derivados de investigaciones en los campos de la biogenética financiados por empresas farmacéuticas y de la salud.

Por ejemplo las plantas medicinales de origen natural, hoy son objeto de investigaciones en estos campos que han originado nuevos productos farmacéuticos para combatir ciertos padecimientos y mejorar la salud humana. Sin embargo aplicando las reglas de la lógica, las normas axiológicas y el mismo derecho, nos percatamos que la explotación de los productos naturales, que antiguamente pertenecían a las comunidades indígenas y que hoy les ha sido despojado tanto de su entorno natural como de su conocimiento por la industria farmacéutica trasnacional, generan devastación ambiental, despojo de reservas naturales y en general transgreden la dignidad humana de los nativos cuando son despojados de su conocimiento en plantas medicinales.

La dignidad humana entonces nos permite entender, que es el límite que debe imponerse frente a todas estas nuevas tecnologías, que incluso han invadido las áreas del genoma humano (Valdés Meza, 2012) ${ }^{4}$, de la clonación y de otros fenómenos que han sido limitados por los instrumentos internacionales en esta materia. En este contexto se impone entonces el uso de la argumentación jurídica, tomando en cuenta la existencia de la disciplina denominada bioderecho o biojurídica, que se caracterizan por ser un conjunto de normas que tienen por objeto la atención al respeto y protección de la vida humana desde su concepción hasta su consumación. (Atienza, 1984)

La argumentación jurídica viene a resultar una herramienta completamente útil en la necesaria relación que se origina entre la bioética y los derechos humanos, ello en virtud de que la bioética regula tanto la vida humana como la conducta de los hombres, en consecuencia se origina el supuesto del respeto al derecho a la vida y principalmente a la preservación de una vida saludable. Todo lo anterior no es obstáculo para dejar a un lado el respeto, promoción, garantía y protección de los derechos humanos en todo Estado de derecho que presuma de mantener un orden social

\footnotetext{
${ }^{4}$ En este rubro, los especialistas han manifestado su preocupación en la posibilidad de determinar genéticamente los organismos, modificando su estructura e información genética, que a la luz del bioderecho se presenta como una preocupación derivada de los eventuales efectos de la manipulación genética, lo que puede representar una inequidad e injusticia social, ya que se daría una diferenciación entre los nuevos miembros de la sociedad, así como la supresión de las libertades individuales y la capacidad de autodeterminación, ya que se fabricarían seres humanos con fines predeterminados.
} 
basado en el respeto de la ley tanto interna como externa y que se encuentra preocupado por sus habitantes.

Por otra parte, en los ámbitos de la literatura jurídica contemporánea (Vásquez Sánchez, Teoría de la argumentación jurídica sobre la justificación de las decisiones judiciales, 2008) se sostiene que la argumentación judicial fue herencia de la argumentación jurídica. Asimismo se explica que la palabra "argumentación" proviene del latín argüo, is, ui, utum, ere, que mantiene dos significados: indicar-demostrar y convencer. Posteriormente se desplaza al verbo argumentum, argumentor, coargüo, redargüir, que representan argumento, argumentar, convencer, refutar y que tiene sus orígenes en la cultura griega. (Vásquez Sánchez, Teoría de la argumentación jurídica sobre la justificación de las decisiones judiciales, 2008)

El ejercicio de la argumentación jurídica accede al conocimiento de la racionalidad práctica, en el campo concreto de la aplicación e interpretación del derecho, lo que se denomina razonamiento judicial (Tamayo y Salmorán, 2007). En estas condiciones, los operadores jurídicos tienen la obligación de justificar sus resoluciones jurisdiccionales y rechazar criterios arbitrarios, evitando la aplicación fría y mecánica de la norma y analizar en lugar de decidir aisladamente.

La argumentación es entendida también como una contienda regulada que presupone la confrontación de argumentos que son sometidos a las reglas del juego. El argumento niega todo lo que le contradice, por esta razón la argumentación designa también la actividad de argumentar. No es igual argumentar que debatir, polemizar o discutir. La primera se encuentra relacionada con las expresiones de razón, razonamiento o racionalidad, entendiéndose esta última como el entendimiento, el espacio donde se encuentra la razón práctica. Las normas jurídicas son razones para la acción. (Tamayo y Salmorán, 2007)

Bajo el anterior enfoque se ha pronunciado el iusfilósofo español Manuel Atienza (Atienza, El sentido del derecho, 2001), quien ha insistido que el uso del derecho para la solución de conflictos en el ámbito jurisdiccional, obliga a motivar toda decisión, mostrando las razones que permiten justificarlas en términos jurídicos, es decir argumentar. Sin embargo, para la toma de decisiones en la sentencia de un juez por ejemplo, se hace necesario contar con una teoría o una filosofía del derecho que le permita mantener una visión integral del problema, ya que ello le facilitará aclarar la buena razón para la solución de una problemática. (Atienza, Cuestiones judiciales, 2001)5.

En base a todo lo anterior se concluye respecto de la relación y dependencia entre la bioética y la argumentación jurídica, que si tomamos en serio a la vida humana, se llega a la conclusión que precisamente la vida humana y su irrestricto respeto, es el principal objeto de estudio de ambas disciplinas.

\footnotetext{
${ }^{5}$ Atienza considera de trascendencia la teoría para la práctica judicial, basada en seis tesis: 1) juzgar es decidir, distinguiéndose entre tomar una decisión y hacerlo en forma decisionista; 2) debe dar razones y motivar sus decisiones; 3) por un lado se decide, se explica o justifica una decisión; 4) Cuando un juez condena a X a la pena $Y$, da un conjunto de razones que justifican su decisión; el juez explica y justifica mostrando causas, razones y motivos que permiten ver una decisión como un efecto de ellas; 5) se justifica una decisión en casos fáciles o difíciles, cuando no existen problemas con las hipótesis normativas, creándose argumentaciones delictivas, y finalmente; 6) la argumentación supone un esquema más amplio de la concepción lógica, ya sea deduciendo argumentos a favor o en contra, lo cual empieza por identificar cuál es el problema que debe resolverse.
} 
Esta conclusión a su vez, nos permite derivar que en el discurso que actualmente se perfila en los ámbitos del pensamiento bioético para solucionar el problema de su disfunción o difusión y acercarla a la eficacia y eficiencia, se hace necesario el desarrollo de una bioética jurídica basado en el respeto de los derechos humanos y en la dignidad humana como pilares del paradigma interpretativo y argumentativo basada en las normas de esta materia, que será el lenguaje que deba utilizarse en la globalidad jurídica frente a la dignificación, protección y elevación de la calidad de vida de todos los seres humanos. ${ }^{6}$

\section{LOS PRINCIPIOS FUNDAMENTALES DE LA BIOÉTICA}

A partir de la Declaración Universal de los Derechos Humanos, suscrita el 10 de diciembre de 1948, se consagró el derecho humano esencial a la vida, así como la igualdad y a la libertad de todos los seres humanos, lo que permitió que todos fuésemos tratados con la misma dignidad. De esto se desprende que los principios fundamentales en los cuales se apoya la bioética corresponden a los de libertad e igualdad, de beneficio social, acceso a la salud y a la justicia en general. Atienza (Atienza, Justificar la Bioética, 1998) sostiene que los principios de la Bioética tienen su origen en una Comisión formada por el Congreso de los Estados Unidos en el año de 1974, encargada de investigar los principios éticos básicos guiadores de la investigación con seres humanos en la biomedicina, y propone, junto a otros autores (Vásquez, 2000), la ponderación de principios de la bioética como modelo de racionalidad práctica. Por ello cobran importancia los instrumentos internacionales que hasta la fecha han sido registrados y de los que a continuación pasamos a enunciar:

a) Declaración Universal sobre el Genoma y Derechos Humanos ${ }^{7}$, la cual señala en su Artículo $1^{\circ}$ que el genoma representa la base de la unidad fundamental de todos los miembros de la familia humana, en este sentido resalta el respeto a la dignidad y derechos de todos los individuos, sin importar sus características genéticas, por ello sostiene que el genoma humano en su estado natural no puede generar lucros o beneficios de ninguna naturaleza.

b) Declaración Internacional sobre los Datos Genéticos Humanos ${ }^{8}$, sostiene que la información genética forma parte del acervo general de datos médicos, por ello son puntualmente relevantes desde un punto de vista cultural para personas o grupos, por lo cual debe otorgárseles un tratamiento riguroso de confidencialidad que deben ceñirse a las prescripciones legales en esta materia.

Este instrumento tiene como principales objetivos el respeto a la dignidad, protección de los derechos humanos, libertades fundamentales, recolección, tratamiento, utilización, conservación de datos genéticos y las muestras biológicas de las que estos provengan, atendiendo al imperativo de igualdad, justicia, solidaridad y prestación de

\footnotetext{
${ }^{6}$ Los principios de universalidad, interdependencia, indivisibilidad y progresividad contenidos en el artículo $1^{\circ}$ de la CPEUM, son básicos como ejemplo de elementos de argumentación jurídica en el discurso del pensamiento bioético del siglo XXI.

${ }^{7}$ Proclama por la Conferencia General de la UNESCO y aprobada el 11 de noviembre de 1997.

${ }^{8}$ Proclama por la Conferencia General de la UNESCO y aprobada el 16 de octubre del 2003.
} 
la debida atención a la libertad de pensamiento, expresión o investigación. Dirigiendo sus objetivos como guía para que los estados conformen su legislación y política nacional en aras de consolidar la debida eficacia de los principios elementales de la bioética.

c) Declaración Universal sobre Bioética y Derechos Humanos ${ }^{9}$, es el principal instrumento internacional que se refiere extensamente a la bioética, el cual aborda las cuestiones éticas relacionadas con la medicina, las ciencias de la vida y las tecnologías conexas aplicadas a los seres humanos, considerando sus dimensiones sociales, jurídicas y ambientales dirigidas a los estados, para su orientación en la toma de decisiones frente a individuos, grupos, comunidades, instituciones y empresas públicas y privadas.

Entre sus objetivos destaca formular un marco universal para establecer los principios y los procedimientos que deben regular a la bioética en los diferentes estados; orientar la acción colectiva, individual, comunitaria, institucional y de la iniciativa privada; promover el respeto de la dignidad humana y proteger los derechos humanos (Tealdi, 2005), velando por el respeto de la vida y las libertades fundamentales de acuerdo al marco internacional normativo en derechos humanos ${ }^{10}$.

Otros principios de la bioética, se basan en el fomento de un diálogo multidisciplinario y pluralista sobre esta disciplina; la promoción de un acceso equitativo a los adelantos de la medicina, la ciencia y la tecnología; la salvaguarda y promoción de los intereses de las generaciones presentes y venideras y la importancia de la biodiversidad y su conservación como una preocupación común de la especie humana.

Se destacan como principios fundamentales el respeto a la dignidad humana, los derechos y libertades fundamentales, y se hace una serie de prevenciones en materia de beneficios y efectos nocivos, así como el cuidado y el tratamiento de todas las personas que se sometan a cualquier tratamiento relacionado con estos ámbitos entre otros. (Ministerio de Justicia y Derechos Humanos de la Nación)

Por otra parte se declara la existencia de principios fundamentales de la bioética basados en la naturaleza común del género humano, como producto de la reflexión ética aplicada a los desarrollos tecnológicos que permiten definir si esos desarrollos afectan o no a la dignidad humana, como es el caso de la experimentación con clones, genomas, embriones, entre otros fenómenos. Bajo este esquema existen tres amplios principios que abarcan este marco:

a) Preservación de la dignidad humana ${ }^{11}$, entendiéndose como la primacía del valor del ser humano sobre las cosas.

\footnotetext{
${ }^{9}$ Proclama por la Conferencia General de la UNESCO y aprobada en octubre del 2005.

${ }^{10}$ La importancia del presente instrumento, es destacada como la postulación fundacional universalista de la bioética.

${ }^{11}$ La dignidad humana también es concebida como el respeto del hombre en cuanto individuo concreto y como objeto y sujeto jurídico titular de derechos y deberes iguales a los de cualquier otra persona, que se concibe como la individualización de la autorepresentación. Vid. Becchi, Paolo, “El principio de la dignidad humana”, Fontamara, México, 2012, p. 37.
} 
b) La igualdad esencial en el núcleo de los seres humanos, ya que todos tenemos la misma naturaleza, somos irrepetibles y en ese sentido tales derechos pudieran negarse a partir de la legalización de la fecundación in vitro, las atenuaciones y despenalizaciones del aborto, el tráfico de órganos entre otros.

c) La indisponibilidad de la vida humana, en el sentido de que ni los hijos son propiedad de los padres, quedando entendido en este principio que nunca es lícito matar a un ser humano inocente; las normas penales han castigado a los autores del homicidio, así la prohibición de homicidio viene a constituir el núcleo esencial de la convivencia civil que es reconocido universalmente y respetado por todos los núcleos humanos.

Bajo este esquema se deriva que la clave de la bioética apoyada en los tres principios antes mencionados, se constituye como defensora de la vida humana además del respeto de esta en todas sus formas, es decir desde su concepción, desarrollo y todas las circunstancias biológicamente humanas que conllevan al proceso de la formación de la vida.

El discurso del pensamiento bioético contemporáneo, abraza las anteriores concepciones y limita su estudio a los quehaceres del médico y de la relación humana de procreación y su relación con todas las tecnologías que conlleva este proceso. No obstante consideramos que como elemento de la argumentación jurídica, la vida humana (Cabrera, 2005) ${ }^{12}$ es el valor supremo que racionalmente debe consagrarse en el respeto irrestricto de la misma, como un derecho humano, pero que implícitamente conlleva su respeto en todas sus fases de desarrollo natural.

En otras palabras, todos los seres humanos tenemos derecho a que la sociedad organizada, el mismo Estado y como consecuencia el mismo gobierno, garanticen que en todo tiempo la vida humana no será arrancada en contra de nuestra voluntad, con motivo de un hecho violento en la cual el Estado deba otorgar el servicio público de seguridad.

En la teoría de los derechos humanos, se apunta la preservación y supremacía de la vida humana frente a cualquier otra institución o valor público, por ejemplo frente a la seguridad del Estado o de las empresas particulares, la misma ley y el mismo Estado como órgano de control social. Por ello cuando ocurre un homicidio violento, provocado por la delincuencia o por la violencia oficial a través de la fuerza represora del Estado que es la policía, el ejército y todos aquellos elementos que utilizan un arma de fuego autorizados por el Estado, en ese momento el Estado incurre en violación de derechos humanos por omisión de cuidado y preservación de la vida humana.

En México los miles de muertos, desaparecidos, víctimas de violación de derechos humanos y demás flagelos reprobables como la tortura, representan en conjunto el fracaso del Estado de derecho. Las leyes, el control social y el mismo derecho penal, han sido incapaces de detener, controlar o disminuir esta ola de violencia gradual y preocupante.

\footnotetext{
${ }^{12}$ La discursiva filosófica aborda este problema desde la matriz argumentativa, basada en la inferencia del silogismo lógico que estatuye: Es moralmente malo suprimir la vida humana o no es moralmente bueno suprimirla.
} 
Los índices de impunidad aumentan alarmantemente: este fenómeno es monitorizado a través de la percepción ciudadana. En esta actividad de medición social, se concluye que el Estado mexicano se encuentra confabulado o es aliado de la delincuencia criminal. Los hechos ocurridos en el mes de octubre del año 2014 en el municipio de Iguala Estado de Gurrero, donde perdieran la vida cuatro estudiantes y desaparecieran más de 43 declarados virtualmente muertos, representa otro crudo escenario de la descomposición social provocada por la crisis del respeto de los derechos humanos que elimina completamente el anhelo del constituyente mexicano plasmado en el Artículo $1^{\circ}$ de la Constitución Política Mexicana.

En estas condiciones, la bioética se erige como instrumento auxiliar en la búsqueda de la paz social local e internacional (Ferrajoli, 2003) ${ }^{13}$, al mantener un margen de preocupación por la preservación de la vida humana, por ello se ha propuesto a la argumentación jurídica, que utilizara principios universales aceptados y proclamados por la Organización de las Naciones Unidas, para utilizarse en el nuevo discurso que habrá de asumir el nuevo pensamiento y la conciencia bioética.

Disciplina de la que se propone, mantenga un estándar ético de compromiso social con la población más vulnerable, que generalmente es la que arroja el inmenso caudal de registro de personas fallecidas en hechos de violencia y que generalmente permanecen impunes los responsables o autores de este flagelo de exterminio humano, sin que el Estado pueda ejercer su ius puniendi o derecho de castigo hacia los responsables de esta conflagración humana.

Por ello la bioética bajo los principios que la rigen y que ya han sido expuestos en el presente apartado, condena la supresión de la vida humana por cualquier medio que no sea el natural o accidental, a través de condenar el uso de la violencia criminal y oficial, sin agotar otros procedimientos convencionales, eficaces y eficientes que combatan a los responsables de la violencia criminal. La bioética en la globalización debe reafirma la defensa de los derechos sociales, como el ámbito marginado del fenómeno del neoliberalismo del siglo XXI. (Ferrajoli, Los derechos humanos en la transformación social: los pendientes en la agenda de la globalización, 2011)

El uso, autorización, transportación y cualquier otro mecanismo o conducta de cualquier persona en las armas de fuego, como maquinaria de exterminio de la vida humana, es completamente reprobable y se condena, toda vez que la violencia existente en sociedades convulsionadas por la delincuencia organizada, como es el caso de México, se debe entre otros factores a la ineficiencia e ineficacia de la procuración y administración de justicia, a la corrupción imperante, de autoridades de todos los órdenes que han permitido el tráfico de armas de fuego, que es el medio por el cual se han venido cometiendo una serie de homicidios violentos.

Cualquier otra muerte violenta, es reprobable e indignante. Cada muerte sin proceso a sus autores ni castigo en debido proceso penal, lesiona la inteligencia y conculca los derechos humanos de cada

\footnotetext{
${ }^{13}$ Precisamente la alternativa de la paz es la propuesta del garantismo frente a la gravedad de la crisis reflejada en la permanente amenaza de guerra en los diferentes países, mediante el uso de la principal garantía de paz prevista en la Carta de la ONU, que en teoría debería formar un monopolio jurídico de la fuerza en manos de las Naciones Unidas, para lo cual se requiere un progresivo desarme y una prohibición de la producción, comercio y tenencia de armas.
} 
víctima cuyos restos yacen en fosas comunes o sepultados clandestinamente en alejadas serranías, ignorados, sin derecho al resarcimiento o el castigo a los autores de su crimen.

El dolor, la desesperación y el desgarre por la pérdida de una persona humana, genera una serie de victimización que abarca a toda una familia o a varias familias. El luto y la desesperanza, son símbolos de destrucción de las familias mexicanas, violaciones que deben ser desterradas en el siglo XXI, como símbolo de globalidad hacia una paz universal, que ha sido anhelada por todos los pensamientos progresistas de todos los tiempos.

\section{CONCLUSIONES}

La bioética ha considerado a la vida humana como uno de los principales valores reconocidos por cualquier sociedad organizada, incluso es su principal fuente de estudio y razón de existir; la bioética se entiende como la ética aplicada que precisamente estudia la conducta ética de los hombres, que toma al hombre de la ciencia de la medicina como ejemplo y que privilegia a fin de exigirle sobre todo el respeto al bios, es decir a la vida humana plena.

Dentro de los principios de la bioética destacan la primacía del ser humano sobre cualquier otra cosa; asimismo reconoce a la igualdad como principio fundamental que todos los seres humanos tienen a su favor. También ha sido reconocida como principio básico a la indisponibilidad de la vida humana, que significa que la vida de los seres humanos no está permitida como objeto dentro del comercio, tratos o convenios de ninguna naturaleza. En este sentido se ha confirmado y demostrado que no es lícito matar a un ser inocente.

La bioética aboga por que en la protección de la vida humana, se contengan proposiciones negativas que representan verdades irrefutables. Tal es el caso de prohibir la supresión de la vida humana a través de prohibir el homicidio como conducta humana reprobable; por ello genera y propone condiciones ideales para que se concrete en todas las sociedades humanas el principio básico de la convivencia respetuosa entre todos los seres humanos. Convivencia y armonía social que universalmente es reconocido y respetado por todos los pueblos. En ello se concretan las condiciones de globalidad jurídica.

El discurso del pensamiento clásico bioético, había limitado sus expectativas a discusiones de rigorismo académico, a veces inaccesible a la población y otras en forma lacónica sin destacar su

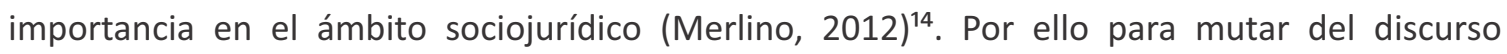
prescriptivo academicista de la bioética, se propone el discurso argumentativo para generar una mayor eficiencia y eficacia en la conveniencia de adoptar los principios internacionales de la bioética plasmados en los instrumentos normativos que han sido destacados en el presente trabajo, a favor de la vida humana y en defensa y protección de la dignidad.

\footnotetext{
${ }^{14}$ Algunas tendencias proponen a la argumentación práctica como método de gestión entre la diversidad de opiniones y representaciones en la bioética.
} 
La argumentación jurídica propone la exposición de razones para justificar decisiones; es a través de principios universales y su correcta exposición, mediante el uso de la lógica formal y sus principios fundamentales, en que la bioética generará una mayor expectativa de solución, proponiendo esquemas estratégicos para resolver los problemas que actualmente se generan en nuestra sociedad derivado de un alarmante y preocupante incremento de índice de violencia que arroja miles de personas que han perdido la vida.

La bioética enfrenta en el siglo XXI ante una globalidad jurídica, el descomunal reto que es preservar e impedir que la vida humana se suprima por la violencia delincuencial y oficial que impera en la sociedad mexicana. No puede minimizarse ningún problema de esta naturaleza, en virtud de que la vida humana es valiosa e importante, superior y preferente frente a otros valores, bienes y cosas. Bioética, argumentación jurídica, derechos humanos, globalidad jurídica y principios universales, son los instrumentos indispensables hacia la construcción de un nuevo mañana forjado en la paz y el orden de todos los seres humanos, mediante la eliminación de la violencia y la venida de un progreso social con leyes más humanas.

\section{REFERENCIASBIBLIOGRÁFICAS}

APARISI MIRALLES, Á. (1997) "EI Proyecto Genoma Humano: algunas reflexiones sobre sus relaciones con el Derecho". España: Tirant Lo Blanch.

ATIENZA, M. (1984) "Problemas abiertos en la filosofía del derecho!. Doxa, Cuadernos de filosofía del Derecho, 32.

ATIENZA, M. (1998) "Justificar la Bioética". Isonomía, Revista de Teoría y Filosofía del Derecho, 7599.ATIENZA, M. (2001) "Cuestiones judiciales". México: Fontamara.

ATIENZA, M. (2001) "El sentido del derecho". España: Ariel.

BERMEJO, J. C., \& BELDA, R. M. (2006) "Bioética y acción social". España: Sal Terrea.

CABRERA, J. (2005) "Estructuración del discurso bioético II. Coherencia, argumentación y tolerancia". En V. Garrafa, \& e. al., Estatuto epistemológico bioético (págs. 239-246). México: Unam-RedbioéticaUnesco.

CARDONA, J. C. (2011) "Bioética y argumentación jurídica". Revista de Bioética Latinoamericana, 1317.CIOMS. (2002) "Pautas éticas internacionales para la investigación biomédica en los seres humanos". Ginebra: OMS.

FERRAJOLI, L. (2003) "La guerra y el futuro del derecho internacional". En G. Strada, \& e. al., No en mi nombre. Guerra y derecho (págs. 22-223). España: Trotta.

FERRAJOLI, L. (2011) "Los derechos humanos en la transformación social: los pendientes en la agenda de la globalización". En A. Obando, \& e. al., Globalización, ciudadanía y derechos humanos (págs. 132136). México: UAEM. 
MERLINO, S. (2012) "La argumentación en la interfaz ética/Biomedicina". Una retórica de colaboración. Retor, 127.Ministerio de Justicia y Derechos Humanos de la Nación. (s.f.). Bioética. El desafío de una declaración universal. Argentina: 2007.

OBANDO, A., \& TEJEDA, R. (2011) "Derecho y justicia en el pluralismo y la globalización". México: UAEM.

PFEIFFER, M. L. (2011) "Bioética y derechos humanos: una relación necesaria". Redbioética, 1.

SÁNCHEZ GÓMEZ, N. (2009) "Derechos humanos, bioética y tecnología". Un enfoque interdisciplinario. México: Porrúa.

TAMAYO y SALMORÁN, R. (2007) "Razonamiento y argumentación jurídica". El paradigma de la racionalidad y la ciencia del derecho. México: UNAM IIJ

TEALDI, J. C. (2005) "La dignidad humana. Filosofía, bioética y derechos humanos". En S. d. Humanos, La dignidad humana. Filosofía, bioética y derechos humanos (págs. 46-48). Argentina: Presidencia de la Nación.

VALDÉS MEZA, E. (2012) "Biotecnología, genética y cultura: un análisis desde la perspectiva del bioderecho". En A. Obando Cabezas, Derechos humanos y justicia en clave constitucional (pág. 191). México: UAEM.

VÁSQUEZ SÁNCHEZ, O. (2008) "Teoría de la argumentación jurídica sobre la justificación de las decisiones judiciales". México: Gudiño Cícero.

VÁSQUEZ SÁNCHEZ, O. (2008) "Teoría de la argumentación jurídica sobre la justificación de las decisiones judiciales". México: Grupo Editorial Gudiño Cícero.

VÁSQUEZ, R. (2000) "Teorías y principios normativos en bioética". Doxa, Cuadernos de filosofía del derecho, 427-448. 